\title{
An Unprecedented Recovery: Why Have We Lost the Plot?
}

Last month, as Joe Biden marked one year as president, the latest economic data came rolling in. US GDP grew by $6.9 \%$ in Q4 2021, with an annualized rate of 5.7\%. Private real consumption had completely recovered to its pre-COVID trend, and household income and real wages were at exactly the level of Q1 2020. Unemployment, after surging to a post-WWII high of $14.7 \%$, had fallen back to $3.9 \%$, below March 2020 levels. Labor force participation, which had fallen from $63.4 \%$ to $60.2 \%$ in early 2020 , had risen again to $61.9 \%$. Business investment had returned to its pre-pandemic trend and risen over 18\% since June 2020.

The speed and scale of this recovery - a near-total return to pre-pandemic levels of GDP, employment, income, consumption and investment in less than two years - is without precedent in American history. By comparison, it took 14 years from the onset of the Great Depression for employment to return to 1929 levels. It took over eight years for unemployment to return to its pre-2008 level after the Great Recession, and real income and consumption have never fully recovered from the Global Financial Crisis and the lost decade that followed.

Without question, the Biden administration's unprecedentedly aggressive fiscal policy has been central to this extraordinary recovery. The US fiscal response was larger than any other G7 country, and the recovery correspondingly stronger. It is difficult to overstate not only how good this news is on its own terms, but also how encouraging it is to see that policymakers learned the right lessons from the Obama administration's errors in 2009, when both the size and composition of the American Recovery and Reinvestment Act (ARRA) were woefully inadequate to the scale of the damage from the Global Financial Crisis. Rather than facing a second lost decade, we now have the prospect of a stronger economy post-pandemic than the one we had at its outset.

One might expect, given this news, that the media and political narratives about the US economy and the Biden presidency would be strongly positive. Instead, current media coverage of both is almost comically negative and pessimistic. One reads daily that we are mired in an economic malaise redolent of the 1970s, with Joe Biden's presidency on the brink of Carter-esque failure. Headlines about the dire threat from single-digit inflation dominate the front pages, and polls suggest voters are more pessimistic about the economy than at any point in decades.

What explains this massive disconnect between the economic reality and the popular narrative? Undoubtedly, a key reason is that the pandemic continues to rage across the country. Yet, one must also look to two other key factors for the entire story: media cues and framing effects, and a failure to seriously benchmark the US economy to other rich countries' experience.

First, we know, from decades of research in political science and other disciplines, that the volume, tone and substance of media coverage deeply shapes political debates and public opinion. Quite simply, US media coverage has been consumed by an incredibly disproportionate focus on inflation. A rough metric of this inflation hysteria is the massive imbalance between news articles with inflation and unemployment in the headline. This ratio was nearly 12-to-1 in 2021, based on available LexisNexis data. This is utterly astounding. Faced with rising-but-stillsingle-digit inflation, while unemployment spiked to an 80 -year high of $14.7 \%$ in April 2020, the media spent the last year writing a dozen articles on the former for every one on the latter.

(C) The Author(s) 2022. Open Access: This article is distributed under the terms of the Creative Commons Attribution 4.0 International License (https://creativecommons.org/licenses/by/4.0/).

Open Access funding provided by ZBW - Leibniz Information Centre for Economics.
Mark Copelovitch, University of Wisconsin Madison, USA. 
Yet the press has been saturated for months now with anecdotes of surging prices for everything from Thanksgiving turkeys to gasoline and milk, along with stories of "average" Americans (some of whom have six-figure incomes and received tens of thousands of dollars in stimulus money in 2020-21) struggling with these price increases. Invariably, these articles reference large nominal price increases, yet few benchmark these to historical levels; gas prices, for example, increased from \$1.68/gallon in April 2020 to \$3.20 in January 2021, but this remains far lower than 2011-14, when prices were $\$ 3.60-\$ 3.90$ and media inflation coverage was all but nonexistent. Likewise, few of these articles mention that the average voter's real consumption and income did not decline at all in 2021. In fact, when one factors in the large spike in median household and real disposable income in February-April (due, again, to the Biden administration's fiscal policies), median real income actually increased this year. Inflation is certainly eroding a large share of recent nominal wages gains, but it is simply not true that the average American's living standards have fallen.

The second reason for the current dominance of the "malaise and inflation" narrative is the deeply parochial nature of the US policy debate. We have spent far too little time benchmarking economic developments at home against those abroad. The view that inflation is a homegrown problem - caused by US fiscal policy - has quite clearly won out in the court of American media and public opinion. Journalists regularly assert that government spending is the key cause of US inflation, and the most prominent and loudest proponents of this view - chief among them former Treasury Secretary Larry Summers - have been given disproportionate airtime to blame Jerome Powell's and Joe Biden's perceived monetary and fiscal policy errors.

To be sure, US inflation is partly policy induced. Given the lack of automatic stabilizer policies, the US fiscal response mainly took the form of direct cash payments, unemployment insurance, and the Paycheck Protection Program. These policies have contributed to a much larger surge in consumer demand and goods consumption than elsewhere, which is part of the reason that inflation is now modestly higher in the US than in other rich countries. But to blame US fiscal policy, alone or even primarily, is a category mistake. High inflation in 2021 is clearly a cross-national phenomenon. Annualized inflation has reached 5.3\% in Germany, 5.4\% in the UK, 5.0\% in the eurozone, and $4.8 \%$ in Canada. Inflation has surged similarly across the entire set of OECD countries. Yet, as Dean Baker has noted, once one controls for differences in how inflation is measured and the impact of global supply chain issues, the data suggest that fiscal policy is responsible for, at most, about $1 \%-2 \%$ of US inflation. Moreover, as Matthew Klein has noted, two-thirds of "excess" US inflation, over and above pre-crisis monthly levels, is attributable entirely to new and used automobiles and energy. Both have little, if anything, to do with US fiscal policy, and they are also major determinants of the inflation increases across the G7 and OECD.

In the US, the fiscal policy tradeoffs were clear: The choice was not between the American Rescue Plan (ARP) and "better" fiscal stimulus (or the adoption of kurzarbeit-style automatic stabilizers) that might have caused less inflation. Rather, the political choice available to the Biden administration was a massive one-time fiscal package of ARP-style policies, or a far smaller and totally inadequate response on the order of Obama's ARRA. An equally rapid recovery with significantly lower inflation was never in the cards because of both politics and structural global factors.

Those in favor of less aggressive fiscal policy are essentially expressing preferences for sustained higher unemployment and a slower recovery, in the hope of possibly having $5 \%$ inflation instead of $7 \%$. In my view, that would have been a poor tradeoff. Even if one thinks inflation is a serious problem, one cannot ignore the unprecedented policy successes of the last year. The contrast between then and now could not be starker, and it is almost impossible to overstate how good this news is, or how modest a price a roughly $2 \%$ inflation premium over our G7 counterparts is to have secured this outcome. And yet, there appears to be no end in sight to the "malaise and inflation" narrative here. The central lesson of the last year is that prolonged recessions and lost decades are entirely a policy choice that aggressive monetary and fiscal responses can avoid. Let us hope that we, and the media, learn that lesson before the next crisis inevitably arrives. 